\title{
PKM PENGEMBANGAN BUDIDAYA BUNGA KRISAN DI KELURAHAN KAKASKASEN KOTA TOMOHON
}

\author{
L H Suot ${ }^{1}$, R Winerungan ${ }^{2}$ \\ 1 Fakultas Ekonomi, Universitas Negeri Manado \\ 1suot@unima.ac.id
}

\begin{abstract}
This community service program through the Community Partnership Program (PKM) is a training for the development of chrysanthemum cultivation in the Kakaskasen Village, Tomohon City. This activity aims to provide guidance and training to flower farmers in the City of Tomohon, dubbed as the City of flowers in order to be able to cultivate Chrysanthemum flowers without having to import from outside the region. This activity needs to be done considering that the city of Tomohon with its nickname which is the City of Flowers in each year carries out an international-scale tourism promotion program called the Tomohon International Flowers Festival (TIFF). So it is very necessary the readiness of the Flower Farmers in supporting such international scale activities. The availability of Chrysanthemum Flowers will be better if the flower farmer in Tomohon City is able to cultivate his own Chrysanthemum flowers without the need to buy from outside the area, it will be more profitable for flower farmers so that every year Tomohon City holds the International Flower Festival to become the biggest income moment for flower farmers in Kakaskasen Village Tomohon City.
\end{abstract}

Keywords: cultivation, chrysanthemum Tomohon, chrysanthemum farmers

\section{PENDAHULUAN}

Kota Tomohon dijuluki sebagai Kota Bunga. Bahkan setiap tahunnya diadakan Festival Bunga Internasional yang pesertanya didatangkan dari berbagai daerah bahkan berasal dari mancanegara. Sebagai Kota Bunga, Kota Tomohon harusnya mampu memproduksi dan membudidayakan tanaman bunga sendiri tanpa harus mengimpor dari luar. Selain itu, kontur dan keadaan Kota Tomohon sangat cocok untuk membudidayakan tanaman.

Kegiatan pengabdian masyarakat ini difokuskan pada permasalahan yang dialami oleh petani bunga Krisan di Kelurahan Kakaskasen, Kota Tomohon, antara lain: (1) kurangnya pengetahuan dan keterampilan petani bunga untuk membudidayakan bunga krisan, (2) Petani bunga perlu mendapatkan pelatihan untuk membudidayakan bunga Krisan.

Kegiatan ini sangat penting untuk dilakukan karena dapat mempermudah usaha petani bunga di Kota Tomohon, serta mampu menambah penghasilan bagi para petani. Selain itu para petani tidak perlu lagi untuk mengimpor tanaman bunga Krisan dari luar daerah yang memakan biaya yang cukup banyak sehingga memberikan keuntungan yang sedikit bagi petani.

Tanaman hias memiliki proses perawatan yang lumayan sulit dari cara pengolahan lahan atau media tanam hingga bisa dipanen untuk dijual. Saat ini Krisan atau yang lebih sering disebut Seruni termasuk bunga yang paling populer dan diminati di Indonesia karena memiliki keunggulan antara lain kaya warna dan dapat bertahan lama, tak lebih dari 70 varietas.

Tanaman hias merupakan berbagai jenis tanaman baik merambat, semak, perdu, maupun pohon yang berfungsi sebagai penghias. Hal tersebut tentunya memperindah, juga mempercantik seperti pada ruangan, halaman rumah, kebun, taman, ruangan, acara upacara, riasan wajah maupun busana.

Budidaya tanaman hias adalah suatu kegiatan dalam mengembangkan tanaman hias mulai dari proses menanam, merawat hingga panen (Lukito:1998). Budidaya tanaman juga merupakan suatu kegiatan positif yang tidak hanya berguna sebagai media untuk meraih keuntungan, namun ada sisi lain yang dapat kita rasakan 
dengan adanya budidaya tanaman ini, salah satu manfaat budidaya tanaman adalah dapat mencegah polusi udara dan membuat udara menjadi sejuk (Rahmat:2004).

Teknik dasar dalam membudidayakan tanaman hias menurut Sanjaya (Sanjaya:1996) dapat dikategorikan 5 teknik diantaranya:

3) Persiapan media tanam

Untuk menyiapkan media tanaman hias harus mengetahui berbagai sifat dan kebiasaan tanaman tersebut hidup dialam, sehingga dalam mengupayakan menjadi tanaman hias yang akan dinikmati disekitar anda.

4) Penyiraman tanaman

Air sangat diperlukan dalam kehidupan tanaman. Didalam sel tanaman, air menjaga turgor agar sel-sel tetap mengembang dan tidak layu.

5) Pemupukan

Tanaman yang hidup membutuhkan zat-zat makanan untuk keberlangsungan hidupnya.

Zat-zat makanan yang mutlak diperlukan untuk pertumbuhan tanaman ialah unsure $\mathrm{C}$, $\mathrm{H}, \mathrm{O}, \mathrm{N}, \mathrm{S}, \mathrm{P}$ dan $\mathrm{K}$.

6) Penempatan tanaman

Tanaman akan mempunyai nilai lebih apabila ditempatkan sesuai dengan kebutuhan, nilai estetika dan yang tidak kalah pentuingnya yaitu dengan memperhatikan sifatsifat serta kebutuhan pertumbuhan tanaman tersebut.

\section{METODE}

b) Materi pelatihan ini dibagi atas 4 bagian yang meliputi:

1) Pengenalan akan budidaya tanaman hias Bunga Krisan.

2) Pengenalan alat dan bahan yang akan digunakan.

3) Penentuan teknik pelaksanaan dan teknik penanaman yang akan digunakan.

4) Pelaksanaan atau praktek penanaman budidaya bunga Krisan. c) Metode dan teknik pelatihan

3) Metode yang digunakan dalam pelatihan ini dalam bentuk seminar dan ceramah dari tim yang sesuai dengan bidnagnya.

4) Peserta diberikan kesempatan untuk bertanya dan bertukar pikiran.

5) Dilakukan pembagian kelompok-kelompok kecil agar praktek dapat dilaksanakan lebih efektif.

6) Praktek pembibitan bunga Krisan dalam pot per kelompok kemudian dievaluasi.

d) Media dan Bahan Pelatihan

Media dan bahan pelatihan berupa Pot kecil, pisau, cangkul kecil, sarung tangan, air, dan bibit bunga Krisan.

Evaluasi dilakukan disetiap akhir kegiatan dan pelatihan.

\section{HASIL DAN PEMBAHASAN}

Petani Bunga di Kelurahan Kakaskasen merupakan warga masyarakat yang sudah menekuni pekerjaan bertani tanaman hias dan menjual tanaman hias sudah sejak lama. Para petani bunga ini memiliki semangat dan menyambut kegiatan pengabdian masyarakat ini dengan sangat baik. Para petani bunga merasa sangat terbantu dengan adanya kegiatan ini, dan tentu saja hal ini bukan hanya menambah pendapatan mereka tetapi juga menambah pengetahuan mereka.

Peserta yang ikut dalam kegiatan ini terdiri dari sebagian besar petani bunga di Kelurahan Kakaskasen Kota Tomohon. Kegiatan pengabdian masyarakat ini dilaksanakan pada akhir minggu yang sudah disepakati bersama sehingga tidak mengganggu kegiatan perdagangan para petani bunga.

Materi yang diberikan kepada para petani mudah untuk dipahami dan dijelaskan dalam bentuk konsep yang sederhana. Para peserta mengharapkan keberlanjutan kegiatan ini untuk diterapkan lagi kedepannya. 
Gambar: contoh bunga krisan hasil budidaya petani bunga Kelurahan Kakaskasen

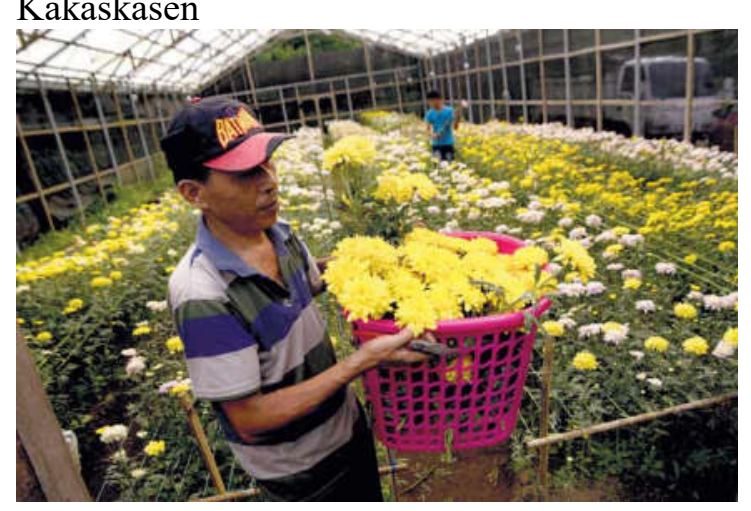

Gambar : Walikota Tomohon ikut dalam Panen Perdana Bunga di Kelurahan Kakasakasen tahun 2018

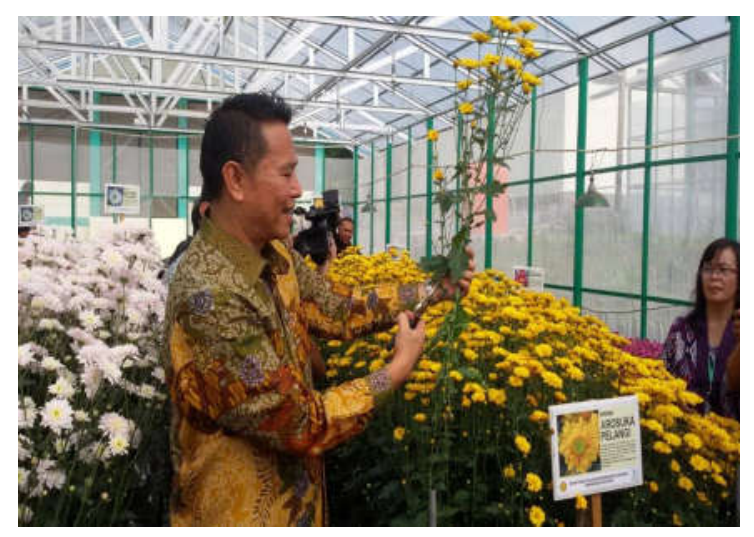

\section{KESIMPULAN}

Petani bunga merasa sangat terbantu dengan adanya kegiatan ini, dan tentu saja hal ini bukan hanya menambah pendapatan mereka tetapi juga menambah pengetahuan mereka

\section{REFERENSI}

H Rahmat Rukmana. 1997. Krisan. Kanisius: Yogyakarta.

Rahmat, Dede. 2004. Teknik Budidaya Krisan. Gajamada: Bandung.

Rukmana dan Mulyana. 1997. Budidaya Krisan. Konisius: Jakarta.

Sanjaya L. 1996. Krisan Bunga Potong dan tanaman Pot yang Menawan. Jurnal Litbang Pertanian.

Lukito AM. 1998. Rekayasa Pembungaan Krisan dan Bunga Lain. Trubus, no 48 